\title{
Electronic and elastic properties of $\operatorname{Ti}_{x} \mathrm{Zr}_{1-x} \mathrm{~N}$
}

\section{Bin Wang ${ }^{1, a}$, Zengbao Wang $^{1, b}$ and Wei Song ${ }^{1, c}$}

${ }^{1}$ Physics and Electronic Engineering Department, Xinxiang University, Xinxiang 453003, China

a Wangbin2013@xxu.edu.cn b wab630105@163.com c chemsw@163.com

Keywords: $\operatorname{Ti}_{x} Z r_{1-x} N$, crystal lattice parameter, elastic constants, elastic modulus, electronic structure

\begin{abstract}
The lattice parameter, elastic modulus, elastic constants and electronic structure of $\mathrm{Ti}_{\mathrm{x}} \mathrm{Zr}_{1-\mathrm{x}} \mathrm{N}(\mathrm{x}=0,0.25,0.5,0.75,1)$ were studied with first-principle pseudopotential plane-waves method. The lattice parameters of $\mathrm{Ti}_{\mathrm{x}} \mathrm{Zr}_{1-\mathrm{x}} \mathrm{N}$ increase with $\mathrm{Zr}$ atoms increasing. Bulk modulus $\mathrm{B}$, shear modulus $\mathrm{G}$ and Young's Modulus E express a monotonously decreasing with Zr concentration. For the shear modulus is proportional to the hardness, the hardness is supposed to be decreasing with $\mathrm{Zr}$ concentration. By analyzing the density of states, $\mathrm{N} \mathrm{p}$ and $\mathrm{Ti}(\mathrm{Zr}) \mathrm{d}$ states hybridized strongly, which form the strong p-d covalent bonds, having positive impact on the hardness.
\end{abstract}

\section{Introduction}

The TiN-ZrN system has gained much attention due to its various charactieristics, such as high melting point, high hardness, corrosion resistance and god-like color of the constitutive binary nitrides $^{[1]}$. Thus TiN-ZrN are widely used as hard coatings, grain refiners and strengthening phases.

There already are some reports on the structural and mechanical properties of (Ti,Zr)N alloys. Single-phase $\mathrm{Ti}_{1-\mathrm{x}} \mathrm{Zr}_{\mathrm{x}} \mathrm{N}$ thin films could be stable up to $1200^{\circ} \mathrm{C}$ and the lattice parameters increase with $\mathrm{Zr}$ content, almost obeying vegard-like behavior. ${ }^{[2]}$ It is found that the Ti-Zr bonds are weaker than Ti-N bonds from the results of band structure calculations. ${ }^{[3]}$ The calculated single-crystal stiffnesses, namely $\mathrm{C}_{11}, \mathrm{C}_{12}$ and $\mathrm{C}_{44}$, gradually decrease with the $\mathrm{Zr}$ concentration. ${ }^{[4]}$

After all, the relationship between elastic properies and electronic structures which is important to explain the change of mechnical properties of $\mathrm{Ti}_{1-\mathrm{x}} \mathrm{Zr}_{\mathrm{x}} \mathrm{N}$, is still not studied. Thus, the theoretical investigations of $\mathrm{Ti}_{\mathrm{x}} \mathrm{Zr}_{1-\mathrm{x}} \mathrm{N}(\mathrm{x}=0,0.25,0.5,0.75,1)$ with the DFT (Density Functional Theory) method were carried out. The lattice parameter, elastic constants, elastic modulus and density of states (DOS) are studied. The relationship between the elastic properties and DOS is reported here firstly.

\section{Method of calculation}

The whole calculations were carried out with the $\mathrm{DFT}^{[5]}$ based on the Cambridge Serial Total Energy Package (CASTEP) plane wave code ${ }^{[6]}$. The interaction of ionic core and valence electrons were described with ultrasoft pseudopotentials. Valence states were corresponding to $\mathrm{N} 2 \mathrm{~s}^{2} 2 \mathrm{p}^{3}$, Ti $3 s^{2} 3 p^{6} 3 d^{2} 4 s^{2}$ and $Z r 4 s^{2} 4 p^{6} 4 d^{2} 5 s^{2}$. The exchange and correlation terms adopted the generalized gradient approximation (GGA) of Perdew-Burke-Ernzerh (PBE) parameterized by Perdew ${ }^{[7]}$ method. With Monkhorst and Pack $k$-point meshes, brillouin-zone integrations were calculated ${ }^{[8]}$. The cutoff energies and the numbers of k-point were set as $600 \mathrm{eV}$ and $14 \times 14 \times 14$.

During the calculation, the unit cell with periodic structure was adopted. The space group of TiN is FM-3M (shown in Fig.1) and there are 4 carbon atoms and 4 titanium atoms in one unit cell. Then, the titanium atoms are gradually substituted with 1, 2, 3 and $4 \mathrm{Zr}$ atoms. 


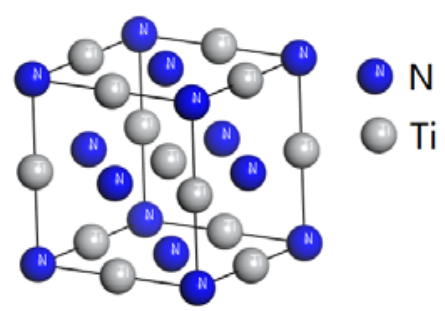

Fig.1 Unit cell of TiN.

\section{Results and discussion}

Crystal lattice parameter. The present lattice parameters after geometry for TiN and $\mathrm{ZrN}$ compared with other experimental and theoretical data are shown in Table 1. It is can be found that our results agree well with other experimental and theoretical data.

Table 1. Present lattice parameters after geometry for $\mathrm{TiN}$ and $\mathrm{ZrN}$ compared with other theoretical and experimental data.

\begin{tabular}{cccc}
\hline \hline & \multicolumn{3}{c}{$a(\AA)$} \\
\cline { 2 - 4 } & present & experiment & theory \\
\hline TiN & 4.25 & $4.24^{[9]}, 4.24^{[10]}$ & $4.24^{[11]}, 4.30^{[12]}$ \\
$\mathrm{ZrN}$ & 4.59 & $4.54^{[11]}, 4.61^{[13]}$ & $4.59^{[14]}, 4.57^{[12]}$ \\
\hline \hline
\end{tabular}

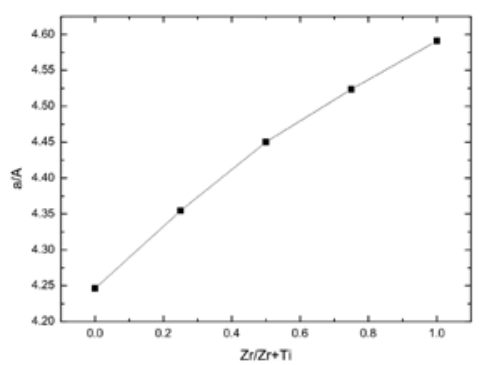

Fig. 2 The equilibrium lattice parameters of $\operatorname{Ti}_{\mathrm{x}} \mathrm{Zr}_{1-\mathrm{x}} \mathrm{N}(\mathrm{x}=0,0.25,0.5,0.75,1)$.

From Fig. 2 it can be found that the lattice parameters a increase almost linearly with $\mathrm{Zr}$ concentration. That's due to the atom radius and the covalent radius of $\mathrm{Zr}$ are bigger than the ones of $\mathrm{Ti}$ atom.

Elastic properties of $\mathbf{T i}_{\mathbf{x}} \mathbf{Z r}_{\mathbf{1 - x}} \mathbf{N}$. The elastic constants $C_{\mathrm{ijkl}}$ are calculated with the equation ${ }^{[15]}$

$$
C_{i j k l}=\left(\frac{\partial \sigma_{i j}(x)}{\partial e_{k l}}\right)_{X},
$$

where $e_{k l}, \sigma_{i j}, X, x$ are Eulerian strain tensor, applied stress tensor and the coordinates before and after deformation respectively. Only three independent elastic constants are for cubic symmetry, $C_{11}, C_{12}$ and $C_{44}$. The bulk modulus B can be deduced from the elastic constants:

$$
B=\frac{c_{11}+2 c_{12}}{3} \text {. }
$$

The isotropic shear modulus $G$ and Young's modulus $E$ are usually used to evaluate the elasticity properties of materials. They are also can be deduced from elastic constants: ( $G$ is regarded as the average of the Voigt and Reuss bounds) ${ }^{[16]}$ :

$$
G=\frac{1}{2}\left[\frac{c_{11}-c_{12}+3 c_{44}}{5}+\frac{5 c_{44}\left(c_{11}-c_{12}\right)}{4 c_{44}+3\left(c_{11}-c_{12}\right)}\right], \quad E=\frac{9 B G}{3 B+G} .
$$



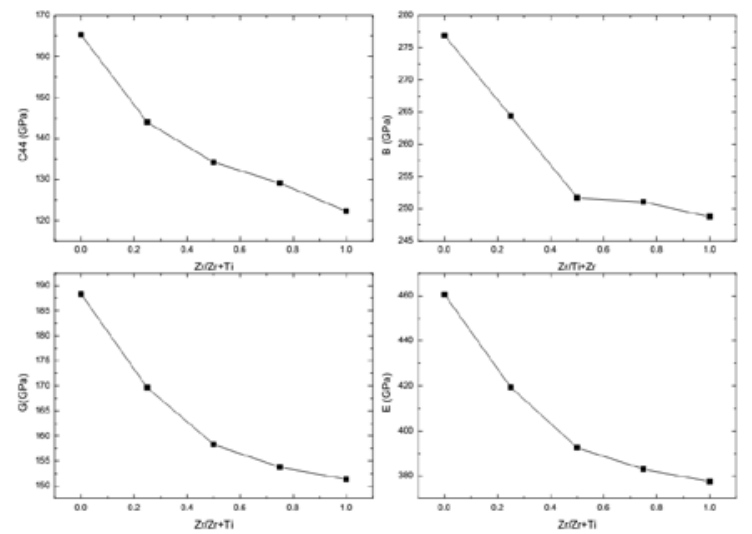

Fig.3 Variations of elastic constant $\mathrm{C}_{44}$, shear modulus $\mathrm{G}$, Young's modulus $\mathrm{E}$ and bulk modulus $\mathrm{B}$ with the concentration $\mathrm{Zr}$ of $\mathrm{Ti}_{\mathrm{x}} \mathrm{Zr}_{1-\mathrm{x}} \mathrm{N}$. (the units in $\mathrm{GPa}$ )

$B$ decreases monotonously with the $\mathrm{Zr}$ atoms increasing, which means the ability of resistance to uniform compression drops with the decreasing $\mathrm{Zr}$ atoms. Moreover, the values of $C_{44}$ and $G$ of $\mathrm{Ti}_{\mathrm{x}} \mathrm{Zr}_{1-\mathrm{x}} \mathrm{N}$ also present a monotonously decreasing order with $\mathrm{Zr}$ atoms increasing, which suggests the ability of resistance to shear strain declined with $\mathrm{Zr}$ atoms increasing. Large value of shear modulus is according to the pronounced directional bonding between atoms ${ }^{[17]}$. Thus with the $\mathrm{Zr}$ concentration increasing, less directional for $\mathrm{Ti}_{\mathrm{x}} \mathrm{Zr}_{1-\mathrm{x}} \mathrm{N}$ the bonding behavior is. Furthermore, shear modulus is directly proportional to the hardness ${ }^{[18]}$. Therefore, the hardness is supposed to be decreasing with the increasing $\mathrm{Zr}$ concentration. In addition, $E$ express a monotonously decreasing order with the $\mathrm{Zr}$ atom increasing, which is according to the decreasing resistance ability of stretching.

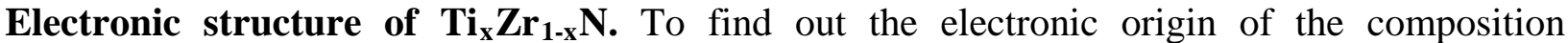
dependence of elastic properties of $\mathrm{Ti}_{\mathrm{x}} \mathrm{Zr}_{1-\mathrm{x}} \mathrm{N}$, the density of states (DOS) are calculated. As the DOS located near the Fermi level are crucial to the bonding, the total density of states (TDOS) and partial density of states (PDOS) near Fermi level for $\mathrm{Ti}_{\mathrm{x}} \mathrm{Zr}_{1-\mathrm{x}} \mathrm{N}$ are listed in Fig.4.

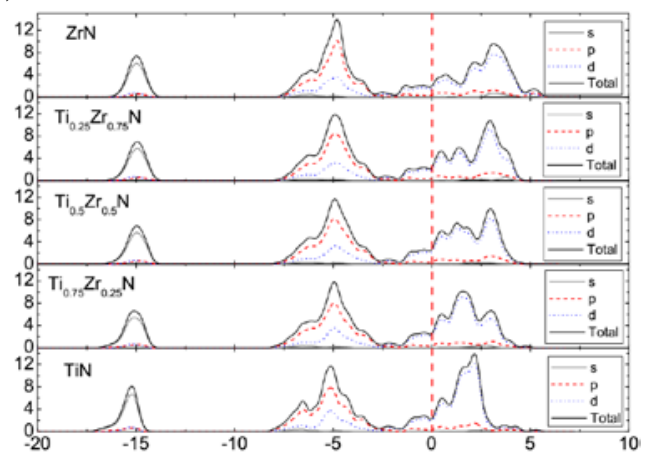

Fig.4 TDOS and PDOS for $\mathrm{Ti}_{\mathrm{x}} \mathrm{Zr}_{1-\mathrm{x}} \mathrm{N}(\mathrm{x}=0,0.25,0.5,0.75,1)$. Fermi level is expressed in dash line at $0 \mathrm{eV}$.

The TDOS and PDOS of $\mathrm{Ti}_{\mathrm{x}} \mathrm{Zr}_{1-\mathrm{x}} \mathrm{N}(\mathrm{x}=0,0.25,0.5,0.75,1)$ are similar. They can be divided into three parts. The first part located below $-13 \mathrm{eV}$ contains predominantly nonmetal $\mathrm{N} 2 \mathrm{~s}$ states, which expressed the electronic core structure. The second part from $-8.4 \mathrm{eV}$ to Fermi level $(0 \mathrm{eV})$, strongly hybridized $\mathrm{Np}$ and $\mathrm{Ti}(\mathrm{Zr}) \mathrm{d}$ states presents the covalent bonding between $\mathrm{Ti}(\mathrm{Zr})$ and $\mathrm{N}$. The third part, from Fermi level to $6.0 \mathrm{eV}$, is mainly derived from metal d orbitals with little nitride p orbitals, which describes metal-metal bonds.

From Fig. 4 it is found that the peaks located near $-15 \mathrm{eV}$ in the first part transfer to the higher energy with the $\mathrm{Zr}$ concentration increasing. The reason is that the electronegativity of zirconium is lower than that of titanium. Based on reference [19], the highly directional coupling between metal $\mathrm{d}$ and non-metal 2p electrons results in a shear-resistive covalent bonding and such bonding gives a positive contribution to the hardness. Therefore, the second part forms the strong p-d covalent bonds, which gives a positive contribution to the hardness. While the third part has a negative impact on the hardness. From Fig.4, the DOSs at the Fermi level increase with the Zr concentration 
also can be found.

\section{Conclusion}

With the DFT and ultrasoft pseudopotentials, the crystal structure, elastic properties, and electronic structure of $\mathrm{Ti}_{\mathrm{x}} \mathrm{Zr}_{1-\mathrm{x}} \mathrm{N}(\mathrm{x}=0,0.25,0.5,0.75,1)$ are calculated and analyzed. The lattice parameters of $\mathrm{Ti}_{\mathrm{x}} \mathrm{Zr}_{1-\mathrm{x}} \mathrm{N}$ increase with the $\mathrm{Zr}$ concentration. $\mathrm{B}, \mathrm{G}$ and $\mathrm{E}$ show a monotonously decreasing order with increasing $\mathrm{Zr}$ concentration, which can be deduced to be that Zr-dopping can decrease the atomic bond strength of TiN. By analyzing the DOS, N p and $\mathrm{Ti}(\mathrm{Zr}) \mathrm{d}$ states hybridized strongly, forming the strong p-d covalent bonds, has a positive impact on the hardness.

\section{Acknowledgement}

Suppored by the Henan Science Bureau Program (Grant no. 132300410007), the Natural Science Foundation of He'nan Department of Education (Grant Nos: 15B150010) Xinxiang University Doctor Initial Research Program (Grant no. 1366020018 and 1366020039) and Science and Technology Innovation Fund of Xinxiang university (Grant no. 15ZP01 and 15ZB25). And the authors specially thank for the software support by the Physics and Electronic Engineering Department, Henan normal University.

\section{References}

[1] S. Niyomsoan, W. Grant, D.L. Olson, B. Mishra, Variation of color in titanium and zirconium nitride decorative thin films, Thin Solid Films 415 (2002) 187.

[2] A. Hoerling, J. Sjölèn , H. Willman, T. Larson, M Oden, L. Hultman. Thermal stability, microstructure and mechanical properties of $\mathrm{Ti}_{1-\mathrm{x}} \mathrm{Zr}_{\mathrm{x}} \mathrm{N}$ thin films, Thin Solid Films 516 (2008) 6421.

[3] G. Abadias, V.I. Ivashchenko, L. Belliard, Ph. Djemia, structure, phase stability and elastic properties in the Ti1-xZrxN thin-film system: Experimental and computational studies, Acta Materialia 60 (2012) 5601-5614.

[4] Kh. Bouamama, P. Djemia, D. Faurie, G. Abadias, structure and elastic properties of single-crystal and polycrystalline $\mathrm{Ti}_{1-\mathrm{x}} \mathrm{Zr}_{\mathrm{x}} \mathrm{N}$ alloys: A computational study, J. Alloy. Compd. 536S (2012) S138-S142.

[5] P.Hohenberg and W. Kohn, Inhomogeneous Electron Gas, Phys. Rev. B 136 (1964) 384.

[6] V. Milman, B. Winkler, J.A. White, C.J. Pickard and M.C. Payne, Electronic structure, properties, and phase stability of inorganic crystals: A pseudopotential plane-wave study, Int. J. Quantum Chem. 77 (2000) 895.

[7] M. Marlo and V. Milman, Density- functional study of bulk and surface properties of titanium nitride using different exchangecorrelation functionals, Phys. Rev. B 62 (2000) 2899.

[8] H.J. Monkhorst and J.D. Pack, On Special Points for Brillouin Zone Integrations, Phys. Rev. B 13 (1976) 5188.

[9] N. Schoenberg, An X-Ray investigation on ternary phases in the Ta-Me-N systems ( $\mathrm{Me}=\mathrm{Ti}, \mathrm{Cr}$, Mn, Fe, Co, Ni). Acta Chem. Scand. 8 (1954) 213 - 220

[10] W.B. Pearson (Ed.), in: Structure Reports, International Union of Crystallography, Oosthock, Scheltema, and Holkema, Utrecht, 1993, p. 170

[11] Y.M. Kim, B.J. Lee, Modified embedded atom method interatomic potentials for the TiC and TiN binary systems, Acta Mater. 56 (2008) 3481-3489 
[12] W. Wolf, R. Podloucky, T. Antretter, F.D. Fischer, First-priciples study of elastic and thermal properties of refractory carbides and nitrides, Philos. Mag. B 79 (1999) 839-858

[13] R. W. G. Wyckoff, Crystal Structures, 2nd ed. (Wiley, New York, 1963), Vol. 1, p. 86.

[14] A. Hao, T. Zhou, Y. Zhu, X. Zhang, R. Liu, First-principles investigations on electronic, elastic and thermodynamic properties of $\mathrm{ZrC}$ and $\mathrm{ZrN}$ under high pressure, Mater. Chem. Phys. 129 (2011) 99-104

[15] W.S. Slaughter, The Linearized Theory of Elasticity, Birkhäuser Verlag, Basel, (2002).

[16] E. Schreiber, O.L. Anderson and N. Soga, Elastic Constants and Their Measurement, McGraw-Hill, New York, (1973).

[17] X.D. Zhang, Z.Y. Jiang, Y.Q. Hou and L.S. Li, Elastic properties of $\mathrm{NaXH}_{4}(\mathrm{X}=\mathrm{B}, \mathrm{Al}), \mathrm{J}$. Phys.:Condens. Matter. 21 (2009) 275401.

[18] S.H. Jhi, J. Ihm, S.G. Louie and M.L. Cohen, Electronic mechanism of hardness enhancement in transition-metal carbonitrides, Nature 399 (1999) 132.

[19] S.H. Jhi, S.G. Louie, M.L. Cohen and J. Ihm, Vacancy Hardening and Softening in Transition Metal Carbides and Nitrides, Phys. Rev. Lett. 86 (2001) 3348. 